\title{
LONG TERM ADMINISTRATION OF EXOGENOUS OXYTOCIN: EFFECTS ON PREGNANCY RATE, AND EMBRYONIC AND FETAL LOSSES IN NILI-RAVI BUFFALOES
}

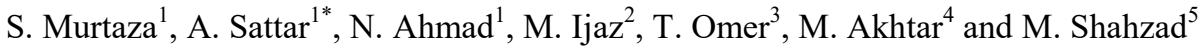 \\ ${ }^{1}$ Department of Theriogenology, University of Veterinary and Animal Sciences (UVAS), Lahore, Pakistan \\ ${ }^{2}$ Department of Clinical Medicine and Surgery, UVAS, Lahore, Pakistan \\ ${ }^{3}$ Department of Statistics and Computer Sciences, UVAS, Lahore, Pakistan \\ ${ }^{4}$ Buffalo Research Institute Pattoki, District Kasur, Pakistan \\ ${ }^{5}$ Nuclear Institute for Agriculture and Biology, Faisalabad Pakistan \\ ${ }^{*}$ Corresponding Author: Email: masattar@uvas.edu.pk \\ The paper was presented in International Buffalo Congress 2019, February 18-20, Lahore, Pakistan
}

https://doi.org/10.36899/JAPS.2020.1.0005

Published online January 02, 2020

\begin{abstract}
It is a common perception among dairy farmers in Pakistan that oxytocin (OT) injection negatively effects on buffalo reproduction parameters. Therefore, current study was conducted to investigate the outcomes of OT on numbers of AI per conception, pregnancy rate, embryonic and fetal losses (EFL). For this purpose, Nili-Ravi buffaloes $(\mathrm{n}=23)$ were randomly divided into three groups, $\mathrm{G} 1 ; \mathrm{n}=7$ (control), $\mathrm{G} 2 ; \mathrm{n}=8$ (low dose 10 i.u.) and $\mathrm{G} 3 ; \mathrm{n}=8$ (high dose 30 i.u.). The OT injection was given twice daily at morning and evening milking until 154 days post calving. At heat, AI was performed. Ultrasonography and blood sampling were done on days 30, 45 and 60 post AI to monitor pregnancy and progesterone, respectively. Results showed significant $(\mathrm{P} \leq 0.05)$ increase of AI services per conception in G2 \& G3 as compared to G1. Furthermore, results revealed that chances of the animals to become pregnant were 0.227 and 0.094 times in low (G2) and high doses (G3) in comparison to control (G1), respectively, and was lower significantly (P $\leq 0.05)$. Similarly, pregnancy rate was remained unaffected and was non-significant $(\mathrm{P}>0.05)$ on day 45 vs day 30 . However, it was significantly $(\mathrm{P} \leq 0.05)$ lower on day 60 vs day 30 . Overall, pregnancy rate was decreased $(\mathrm{P} \leq 0.05)$ in oxytocin treatments comparable to control. Parity and days in milk had no significant effect on pregnancy rate among treatments (G1, G2 and G3), respectively. Moreover, EFL losses were non-significant $(\mathrm{P}>0.05)$ among treatments but losses trend was more in G2 \& G3 parallel to G1. Result also showed non-significant $(\mathrm{P}>0.05)$ decrease in $\mathrm{P} 4$ on days 30 and 45 while significant $(\mathrm{P} \leq 0.05)$ on day 60 in $\mathrm{G} 2 \& \mathrm{G} 3$ as compared to $\mathrm{G} 1$ among treatment groups. It may be concluded that long term OT injections of both low and high doses cause significant losses in terms of increase in AI services per conception and decrease pregnancy rate with higher EFL in Nili-Ravi buffaloes.
\end{abstract}

Keywords: Oxytocin, pregnancy rate, EFL losses, Nili-Ravi buffalo.

\section{INTRODUCTION}

Buffalo is the key dairy animal of the Pakistan which is considered as vital source of income and poverty alleviation in the rural area of the country. At the same time, this animal shows poor reproductive performance with an average 230 and 250 days service and dry periods, respectively (Khan et al., 2007). Unfortunately, the poor managemental practices and scarcity of information regarding reproductive physiology of NiliRavi buffalo has put its reproductive and productive potential at inertia. However, there are some issues of serious nature to reproductive health of this animal which lead to poor reproduction and fertility rates. These includes: delay in puberty, increase in inter estrous interval, decrease in conception rates, and increase in embryonic losses, abortions and prolong calving interval (Usmani et al., 2001; Qureshi and Ahmad, 2008;
Warriach et al., 2012). These are the foremost causes of low reproductive efficiency in buffalo thus lengthening non-productive life. Generally, major reproductive obstacles in buffaloes are lower pregnancy rate and higher embryonic and fetal losses which are often neglected at farm levels. All of these parameters, are not only reported to be effected in buffaloes but also in cattle and other farm animals which are considered as traits of economic importance (Yildiz and Erisir, 2006) for dairy farmers.

There are various infectious and non-infectious components which can modulate the pregnancy rate, embryonic and fetal losses in cattle and buffaloes (Lobago, 2007; Rossi et al., 2008; Qayyum et al., 2018). Qayum et al., (2018) recently studied pregnancy rate, embryonic and fetal losses during different breeding seasons by using various breeding tools and discussed possible reasons of low pregnancy rate in lactating Nili- 
Ravi buffalo. Such lower rate of pregnancy is mostly attributed and linked to disturbance in internal hormonal regulatory mechanisms that ultimately results in embryonic losses (Yildiz and Erisir, 2006; Campanile and Neglia, 2007). Due to hormonal imbalance, the follicular steroidogenic activity is altered and may be suggested that it mostly causes the lowering of fertility in buffalo (Ali, 2015). In addition to hormonal changes, environmental heat stress and type of housing provided to the animal can also serve as effective source of embryonic losses (Hansen, 2014; Dash et al., 2016). An earlier study shows that embryonic mortality was higher between days 31 and 55 of gestation in dairy cattle (Forar et al., 1996). These types of early losses are one of the major reasons behind repeat breeding (Singh et al., 2005) but contributory factors remain unidentify in these dairy animals. There are some studies that describe the seasonal and environmental effects on pregnancy rate and embryonic losses in buffaloes. These embryonic and fetal losses are the leading reasons of pregnancy failure in these animals during transition period when day length increases (Rosso et al., 2010; Campanile et al., 2016). According to one study, embryonic losses have been reported up to $20 \%$ (days 21-45) in riverine buffaloes and are higher when compared to cattle (Campanile et al., 2005). Similarly, in another study, fetal losses have been observed 8-13\% (days 46-90) in buffaloes (Vecchio et al., 2007). In spite of these reasons, some husbandry practices (Fricke, 2002) are considered as contributory factors of low pregnancy rates in buffaloes. Among these practices, unnatural milking practice like regular use of exogenous oxytocin in buffaloes for milk let down may be one of the cause of repeated estrus, delayed ovulation, poor pregnancy rates, embryonic and fetal losses (Ahmad et al., 2000; Mustafa et al., 2008; Qureshi and Ahmad, 2008; Shahid et al., 2016). This is because its regular exogenous administration may lead to elevate the level of oxytocin in blood which is believed to be having potential to initiate luteolytic activity (Lemaster et al., 1999; Yildiz and Erisir, 2006), hence, can result into poor pregnancy rates in term of CL regression and leads to embryonic and fetal losses. This oxytocin may lead to luteal regression by driving the release of prostaglandin $(\mathrm{PGF} 2 \alpha)$ from the endometrium and inhibiting the progesterone production (Fuchs et al., 1996; Balaguer, 1999; Lemaster et al., 1999).

The oxytocin is one of the major hormones commonly used for milk let down and is considered to be involved directly or indirectly with reproductive performance of lactating animals. Mustafa et al., (2008) have reported that about $23.33 \%$ of the buffaloes and $25 \%$ of the cattle show repeated estrus due to frequent use of exogenous oxytocin. One study in the past showed only $30 \%$ pregnancy rate in oxytocin injected mare parallel to control which is $50 \%$ immediately after AI (Rigby et al., 1999). According to another study, Yildiz and Erisir, (2006) found that 37.5\% embryos were lost when oxytocin was injected after insemination in dairy cows. Based on different surveys, it is hypothesized that the uncontrollable use of oxytocin in buffaloes is responsible for their poor production and reproduction (Mustafa et al., 2008). There are some studies which explain the adverse effect of oxytocin injection on general health (Iqbal et al., 2013; Iqbal et al., 2015) while others on reproductive health (Ahmad et al., 2000; Mustafa et al., 2008) in lactating buffaloes, especially Nili-Ravi buffaloes. These effects on reproductive health efficiency are in terms of low pregnancy rate, embryonic and fetal losses in buffaloes (Ahmad et al., 2000; Ahmad and Aleem, 2006; Mustafa et al., 2008) and cows (Lemaster et al., 1999; Yildiz and Erisir, 2006). Some studies present that oxytocin infusion has no effect on pregnancy in cows (Lafrance and Goff, 1985; Kubo et al., 2018) but not well defined in buffaloes. In Pakistan especially Punjab, oxytocin injection is indiscriminately used at the time of milking for milk let down during whole lactation in buffaloes when young calves died or sold. Buffalo farmers regularly use this vary injection for milk let down even after breeding although claiming poor conception and pregnancy rates, embryonic and fetal losses. Such misconceptions about harmful effects of long term use of exogenous oxytocin on the reproductive health of buffaloes are very common in the fields which are often highlighted on electronic and print media. According to literature available, no work has been conducted so for to evaluate the effect of long term administeration of exogenous oxytocin from calving to heat till day 60 post AI to monitor the reproductive performance in terms of pregnancy rate and embryonic and fetal losses (EFL) in buffaloes. Therefore, this experiment has been performed under the same circumstances as dairy farmers usually do in field condition where they use oxytocin injection for prolong time in buffaloes for milk let down and often show negative perception about its usage at subsequent breeding. To verify or contradict this perception, current study was planned and conducted with objectives to investigate the long term effect of exogenous oxytocin administration on numbers of services per conception, pregnancy rate, embryonic and fetal losses (EFL) in NiliRavi buffaloes.

\section{MATERIALS AND METHODS}

Selection and management of animals: The present study was conducted during breeding season of buffaloes (October to March) at Buffalo Research Institute (BRI), Pattoki Kasur, Pakistan after approval from animal care and ethics committee, University of Veterinary and Animal Sciences Lahore, Pakistan. For this purpose, a total of 23 lactating Nili-Ravi buffaloes (without any peri-partum disorder) were randomly selected and 
divided into three groups: G1, G2 and G3 where controlsaline $(\mathrm{G} 1 ; \mathrm{n}=7)$, low dose 10 i.u. $(\mathrm{G} 2 ; \mathrm{n}=8)$ and high dose 30 i.u. $(\mathrm{G} 3 ; \mathrm{n}=8)$. At the start of experiment, average body condition scores (BCS), age (years), weight $(\mathrm{kg})$ and parity in three treatments groups were same and non-significant among each group (Table 1). Uniform feeding and watering were provided to each animal in all three groups. Routinely, each buffalo was provided $50 \mathrm{~kg}$ green fodder with $5 \mathrm{~kg}$ wheat straw and $4 \mathrm{~kg}$ concentrates. Crude protein (CP; \%) analysis values for green fodder, wheat straw and concentrates were $19 \%$, $2.50 \%$ and $17 \%$, respectively. Generally, total dry matter intake of feed and fodder was $21 \%$ and requirement was $16 \%$ per $\mathrm{kg}$ approximately at the farm.

Experimental procedure: The oxytocin (OT) was injected@10 i.u. and 30 i.u. in G2 and G3 while G1 with normal saline, respectively, twice daily $i$-e morning and evening at the time of milking within one week of calving till 154 days post calving. On natural estrus, animals were breed twice through artificial insemination (AI) at the interval of 24 hours by a single person and numbers of services per conception received by each animal in all oxytocin administered groups including control were recorded. Ultrasonography was performed to monitor pregnancy as well as embryonic and fetal losses in all three groups of animals on days 30, 45 and 60 of post AI. Blood samples $(5 \mathrm{~mL})$ were collected on days 30, 45 and 60 post $\mathrm{AI}$ at the time of pregnancy diagnosis. Serum was separated from blood cells after centrifugation at 3000 revolution per minute for three to five minutes. Separated serum was placed at $-20 \mathrm{c}$ in freezer and then was transferred to RIA Laboratory, Nuclear Institute for Agriculture and Biology (NIAB) Faisalabad, Pakistan for progesterone (P4) analysis. Corpus luteum (CL) status was assessed as an analogue to progesterone analysis against their respective pregnancy judgment days.

Statistical analysis: Binary logistic regression was used to check the relationship of pregnancy status (dichotomous variable) by considering the treatment and number of days as independent variables. Following is the equation of logistic multiple variables regression model

Model:

$Y_{i}=\alpha+\beta_{1} T_{1 i}+\beta_{2} T_{2 i}+\beta_{3} D_{3 i}+B_{4} D_{4 i}+B_{5} P_{5 i}+\beta_{6} M_{6 i}+\mu_{i}$ Where, $Y_{i}=1$, if the pregnant, $=0$, if not pregnant, $T_{1 i}=1$, if the dose is low, $=0$, if the dose is control, $T_{2 i}=1$, if the dose is high, $=0$, if the dose is control, $D_{3 i}=1$, if the day is $45,=0$, if the day is $30, D_{4 i}=1$, if the day is $60,=0$, if the day is $30, P_{5 i}=$ parity, $M_{6 i}=$ days in milk

Association between embryonic and fetal losses among treatment groups was assessed by utilizing the Fisher Exact Test. One way Analysis of Variance (ANOVA) was used to determine the differences among treatment groups for numbers of AI services per conception and progesterone concentration by using the SPSS 20 software. Before using ANOVA, normality was checked through Shapiro Wilk Test. In case of nonnormal data, Fractional Rank Transformation was applied to fulfill the condition for ANOVA. The Duncan Multiple Range (DMR) test by Duncan (1955) was further applied to test the significance between means of different treatment groups. The $\mathrm{P} \leq 0.05$ was considered significant for all analysis.

\section{RESULTS}

In the present study, results showed significant $(\mathrm{P} \leq 0.05)$ increase of numbers of AI services per conception in oxytocin treated groups; G2 \& G3 as compared to control group G1 (Fig. 1). The results of treatments effects were reflected in the form of odd ratios (Table 2). From the results, the odd ratio of low dose versus control showed that there were only 0.227 times (95\% CI $=0.058-0.892)$ chances of buffaloes being pregnant in low dose as compare to control. This indicated that pregnancy rate was decreased significantly $(\mathrm{P} \leq 0.05)$ in low dose $(\mathrm{G} 2)$ as compared to control $(\mathrm{G} 1)$. Moreover, results showed that the performance of high dose in comparison to control was 0.094 times only $(95 \%$ $\mathrm{CI}=0.020-0.451)$. This depicted that chances of buffaloes to become pregnant because of high dose (G3) was significantly $(\mathrm{P} \leq 0.05)$ low as compared to control $(\mathrm{G} 1)$. Moreover, from the result, it was revealed that pregnancy was decreased significantly $(\mathrm{P} \leq 0.05)$ in both injected doses of oxytocin (high and low) as compared to control. Similarly, the results of odd ratio explained 0.310 time (95\%, CI $=0.077-1.245)$ chances of the buffaloes to become pregnant on day 45 vs day 30 of post AI, and was non-significant $(\mathrm{P}>0.05)$. Whereas, on day 60 vs day 30 of post AI, there was only 0.175 times $(95 \%, \mathrm{CI}=0.039$ 0.780) chances of the buffaloes being pregnant. Hence, result displayed that pregnancy was significantly $(\mathrm{P} \leq 0.05)$ lower on day 60 parallel to day 30 of post AI. Further results revealed that parity and days in milk had non-significant $(\mathrm{P}>0.05)$ association with pregnancy rate among three treatment groups (G1, G2 and G3). Approximately, $71.4 \%$ animals got pregnant while remaining $28.6 \%$ remained non pregnant on day 30 of post AI in control group (G1). The ratio of pregnancy in low dose (G2) and high dose (G3) treatment groups were $50 \%$ and $37.5 \%$, respectively. Apparently, the control 
group (G1) animals had $40 \%$ more ratio to get pregnant as compared to the injected groups (G2 \& G3). Similarly, on day 45 of post AI, $57.1 \%$ of the animals had pregnancy in G1, 25\% in G2 and $12.5 \%$ in G3, respectively. On day $60,57.1 \%$ and $12.5 \%$ of the animals in control and low dose groups were pregnant, respectively (Fig. 2). However, none of the animal got pregnant who received the high dose of oxytocin treatment. It was also noted that only one animal was pregnant who received the low dose despite the fact that other 80 percent belonged to control group. From the results and observation, it was found very clear that overall $57.1 \%$ animals remained pregnant in control group (G1) while in both oxytocin injected groups (G2 \& G3), it was only $6.2 \%$. Non pregnant ratio was $42.9 \%$ and $93.8 \%$ in control (G1) and overall oxytocin treated groups (G2 \& G3), respectively (Fig. 3).

In present result, it was seen that there was no significant $(\mathrm{P}>0.05)$ relationship found between treatment groups (G1, G2 \& G3) and any interval of pregnancy. Animals who received low dose and high dose showed $50 \%$ and $66.7 \%$ more embryonic losses on day 45 (Fig. 4). Whereas, only $20 \%$ animals under saline treatment were gone to embryonic losses state, which was less than twice and thrice approximately with respect to low dose and high dose. There was no fetal loss observed in control group (G1), but in low dose injected group (G2) fetal loss increased to $50 \%$ and in high dose group (G3), it was much more observed up to $100 \%$ (Fig. 5). There was $20 \%$ overall loss observed in control (G1), while $85.7 \%$ fetal loss was observed collectively in injected groups (G2 \& G3). Result of current study unveiled that treatments effect on progesterone concentration remained identical $(\mathrm{P}>0.05)$ on days; 30 and 45 . However, it was seen that progesterone concentration was significantly $(\mathrm{P} \leq 0.05)$ drop in $\mathrm{G} 2$ and $\mathrm{G} 3$ as compared to $\mathrm{G} 1$ on day 60 of post AI (Fig. 6).

Table 1. Days in milk, body condition score (BCS), body weight (kg), age (days) and parity of Nili-Ravi buffaloes at the start of experiment $(M e a n \pm$ SE)

\begin{tabular}{|c|c|c|c|c|}
\hline \multirow[t]{2}{*}{ Parameters } & \multicolumn{3}{|c|}{ Treatment groups } & \multirow[t]{2}{*}{$P$ value } \\
\hline & $\begin{array}{c}\text { Control (saline) } \\
(\mathbf{n}=7)\end{array}$ & $\begin{array}{c}\text { Low dose (10 i.u.) } \\
(n=8)\end{array}$ & $\begin{array}{c}\text { High dose (30 i.u.) } \\
(n=8)\end{array}$ & \\
\hline Days in milk & $6.85 \pm 1.43$ & $6.87 \pm 1.87$ & $5.00 \pm 1.51$ & 0.649 \\
\hline $\mathrm{BCS}$ & $3.28 \pm 0.18$ & $3.00 \pm 0.18$ & $2.87 \pm 0.22$ & 0.373 \\
\hline Body weight $(\mathrm{Kg}) *$ & $513.00 \pm 20.26$ & $534.87 \pm 19.37$ & $526.87 \pm 34.01$ & 0.840 \\
\hline Age (year) & $5.71 \pm 0.63$ & $6.31 \pm 0.45$ & $6.18 \pm 0.53$ & 0.722 \\
\hline Parity & $2.14 \pm 0.55$ & $2.37 \pm 0.42$ & $2.50 \pm 0.42$ & 0.863 \\
\hline
\end{tabular}

*kilogram, n: number of observation,

$\mathrm{CON}=$ control group, without oxytocin administration

LOW $=10$ i.u. oxytocin intramuscularly morning evening for 154 days postpartum

$\mathrm{HIGH}=30$ i.u. oxytocin intramuscularly morning evening for 154 days postpartum

Table 2. Summary of multivariable logistic regression model for pregnancy rate, parity and days in milk in different treatment groups in Nili-Ravi buffaloes

\begin{tabular}{lcccc}
\hline \multicolumn{1}{c}{ Variables } & $\begin{array}{c}\text { Coefficient } \\
\text { (B) }\end{array}$ & $\begin{array}{c}\text { Odds ratio } \\
\text { EXP(B) }\end{array}$ & $\begin{array}{c}\text { 95\% CI } \\
\text { OR }\end{array}$ & P value \\
\hline Pregnancy rate in low dose (G2) vs control (G1) & -1.484 & 0.227 & $0.058-0.892$ & 0.034 \\
Pregnancy rate in high dose (G3) vs control (G1) & -2.361 & 0.094 & $0.020-0.451$ & 0.003 \\
Pregnancy rate at day 45 vs day 30 post insemination & -1.172 & 0.310 & $0.077-1.245$ & 0.099 \\
Pregnancy rate at day 60 vs day 30 post insemination & -1.745 & 0.175 & $0.039-0.780$ & 0.022 \\
Parity & -0.475 & 0.622 & $0.353-1.095$ & 0.100 \\
Days in milk at the start of experiment & -0.054 & 0.947 & $0.812-1.105$ & 0.489 \\
\hline
\end{tabular}

$\mathrm{CI}=$ Confidence interval, significant at $\mathrm{P} \leq 0.05$ 


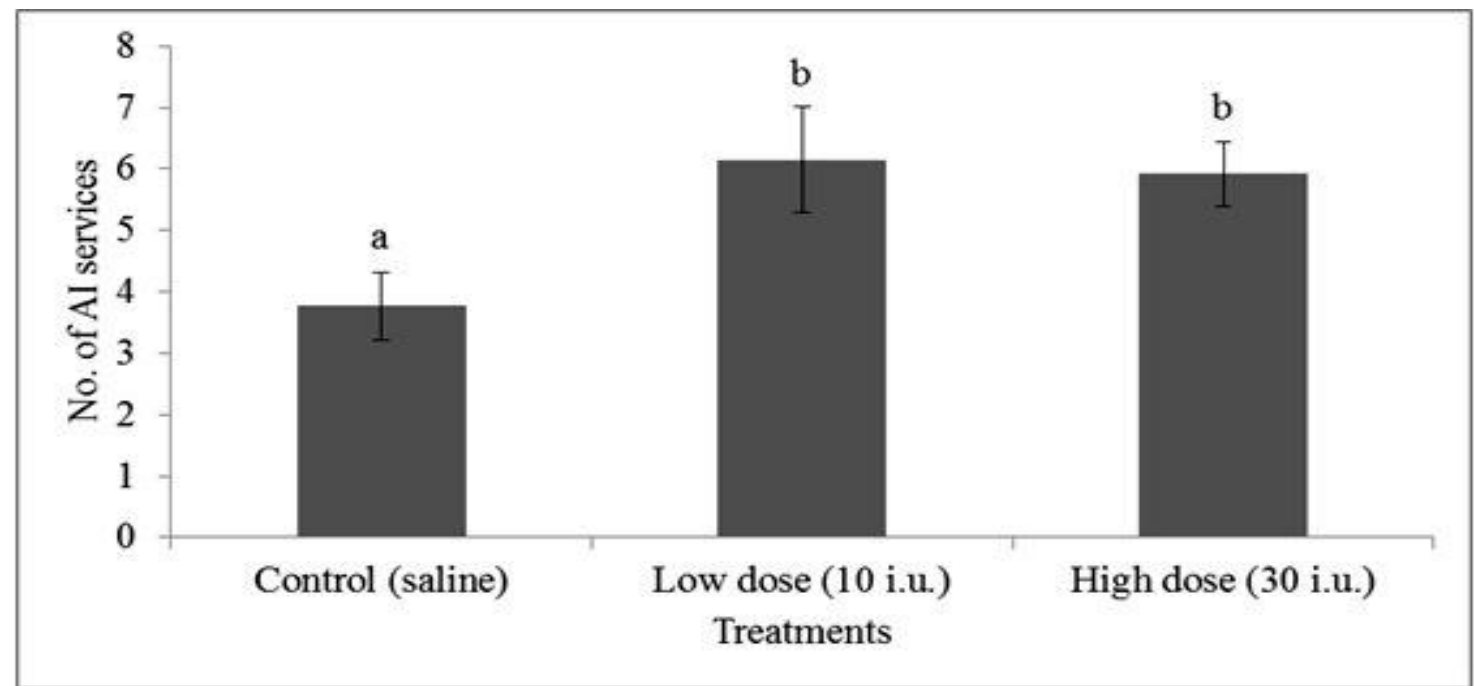

Fig.1. Lower case different superscripts denote the significance $(P \leq 0.05)$ among treatments for numbers of $A I$ services per conception in Nili-Ravi buffaloes

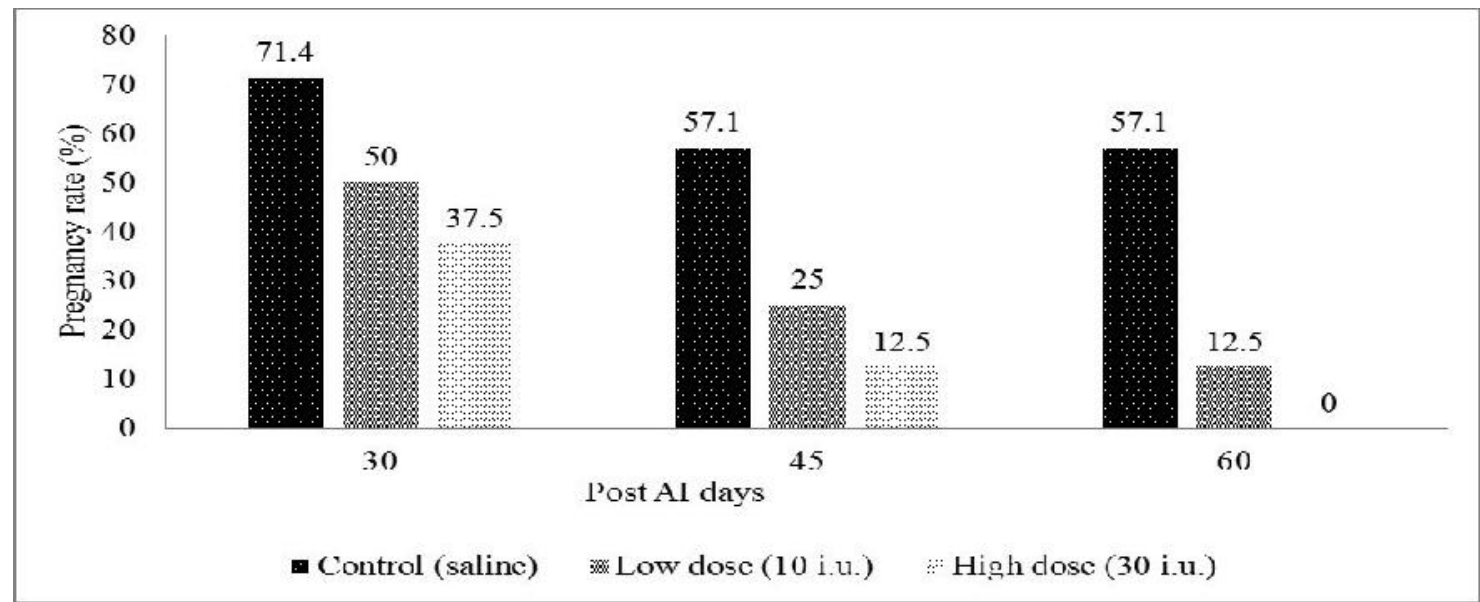

Fig. 2. Percent effect of oxytocin injection on pregnancy among treatments at predetermined post AI days in NiliRavi buffaloes

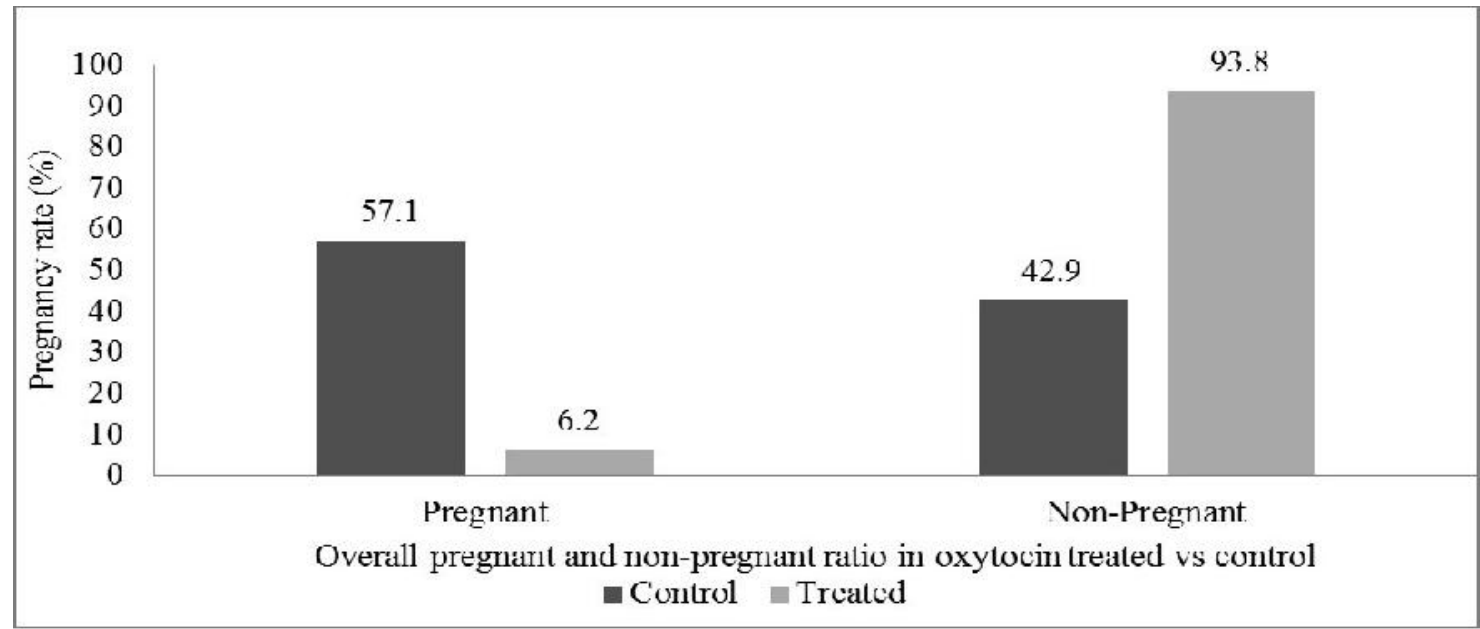

Fig. 3. Difference between control and combined oxytocin treated groups over pregnant and non-pregnant status in Nili-Ravi buffaloes 


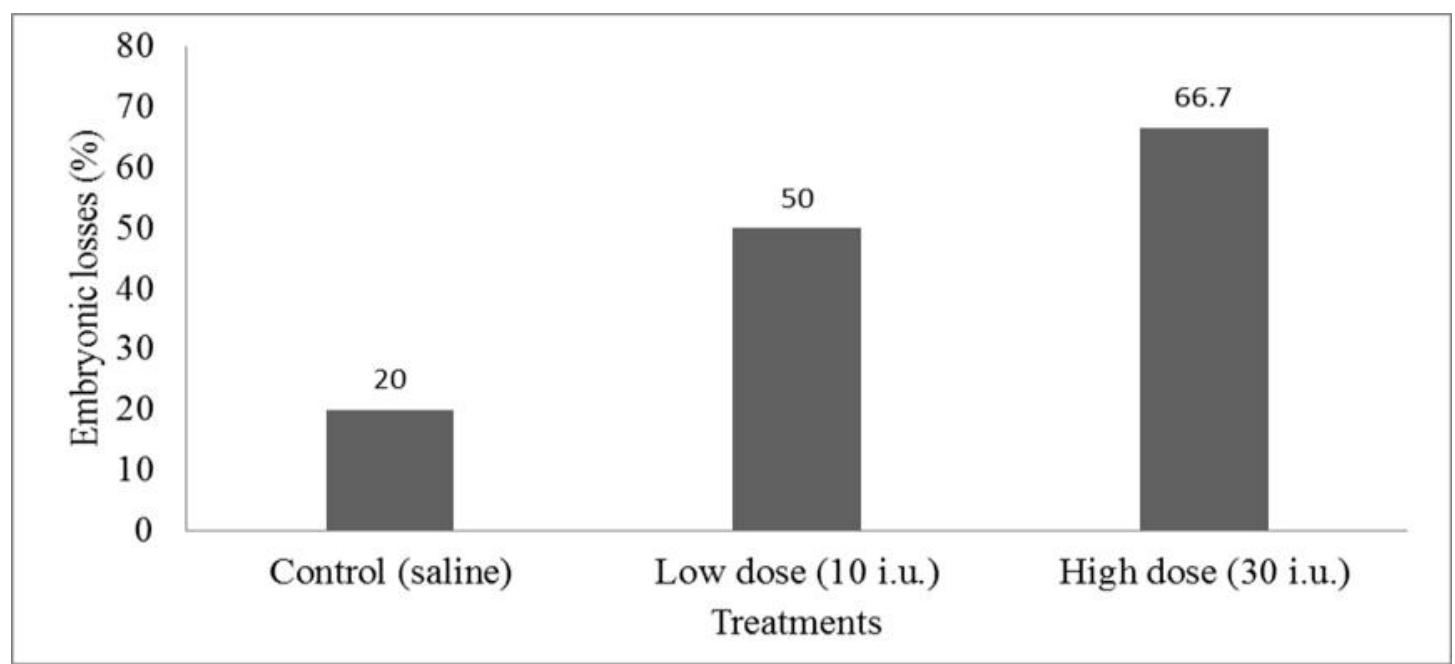

Fig.4. Rate of embryonic losses between control and oxytocin treatments in Nili-Ravi buffaloes

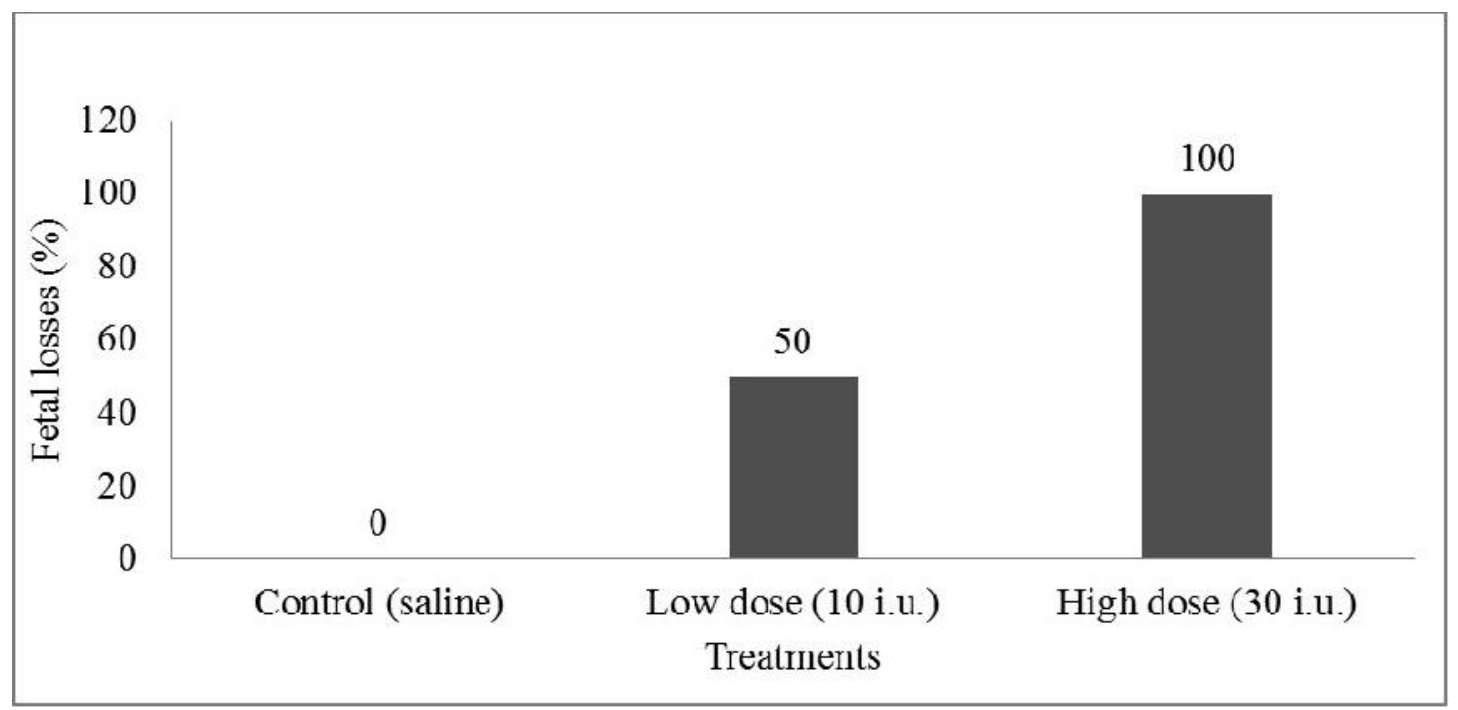

Fig. 5. Rate of fetal losses between control and oxytocin treated groups in Nili-Ravi buffaloes

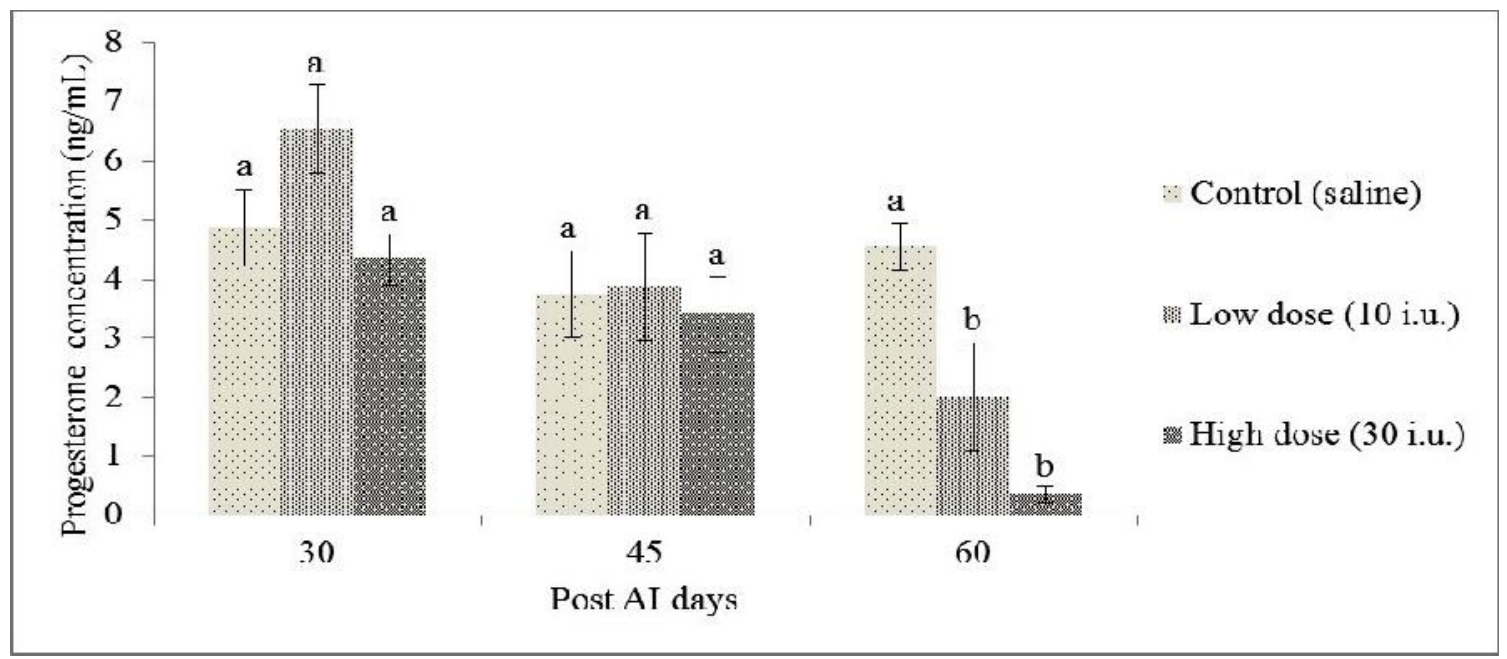

Fig. 6. Progesterone concentration ( $\pm \mathrm{SE}$ ) in treatment groups at predetermined post AI days Lower case different superscripts denote the significance $(\mathrm{P} \leq 0.05)$ among treatments 


\section{DISCUSSION}

The aim of this study was to understand whether a long term use of exogenous oxytocin could influence the number of AI services per conception, pregnancy rate, embryonic and fetal losses in lactating Nili- Ravi buffaloes. For this purpose, the animals were administered with oxytocin injection twice daily within one week of post calving for 154 days. The result of present study revealed that numbers of AI services per conception received by oxytocin treated groups (G2 and G3) were more $(\mathrm{P} \leq 0.05)$ as compared to control $(\mathrm{G} 1)$. These findings are contrary to the one study in dairy cows (Barret et al., 2009) where single time oxytocin or carbectocin administration had no effect on insemination per pregnancy in normally calved animals. Earlier no study was conducted in buffaloes to indicate consequences of regular use of oxytocin injection on numbers of services per conception provided at subsequent heat till day 60 of post AI. This is the first to report the outcomes of long term usage of exogenous oxytocin administration on numbers of AI services per conception provided to each animal for conception in treatments groups in Nili-Ravi buffaloes.

As far as pregnancy rate, results of odd ratio depicted that pregnancy rate was significantly $(\mathrm{P} \leq 0.05)$ affected by low dose and high dose in comparison to control and was significantly $(\mathrm{P} \leq 0.05)$ lower in two oxytocin treatment groups (G2 and G3) on day 60 versus control group (G1), whereas, non-significant differences $(\mathrm{P}>0.05)$ was seen on day 30 and 45 of post AI among three treatments. These results are in accordance with previous reports of different researchers in buffaloes (Ahmad et al., 2000; Mustafa et al., 2008) and cows (Lemaster et al., 1999; Ahmad et al., 2000; Yildiz and Erisir, 2006; Mustafa et al., 2008) but opposite to the findings of Barret et al., (2009) and Kubo et al., (2018) in dairy cows where they used oxytocin injections on days: $12,14 \& 16$ of post AI, and no effect was seen on early pregnancy. Similar type of result was also reported in dairy cows (Gümen et al., 2011) where conception rate was decreased following oxytocin injection at insemination but opposite outcomes in repeat breeder cattle (Matho et al., 2008). The difference in the results of pregnancy rates in various reported studies and current study is due to different treatment duration, dosages, route of administration and species variances. In some other studies, it had been reported that exogenous oxytocin administered cows were at higher risk in terms of lower conception rates, pregnancy losses and reduced conception or pregnancy rates (Lemaster et al., 1999; Yildiz and Erisir, 2006; Gümen et al., 2011). This decrease in the pregnancy rates were considered due to negative impact of oxytocin injection on uterus which stimulated stronger contraction as reported in one invitro study in cow when exogenous oxytocin is injected either in normal or puerperal uterus (Heppelmann et al., 2018). Similarly, it may have negative effect on corpus luteum (CL) resulting into low progesterone concentration in oxytocin treated groups (G2 \& G3) as compared to control group (G1) which ultimately led to reduce pregnancy rates. This diminution in the CL size was analogous to decrease in P4 concentration and may be apparently due to indirect exogenous oxytocin stimulated release of PGF2 $\alpha$ from uterus through utero-ovarian artery which influences the regression of CL and in turn causes the decline in P4 in G2 and G3 as compared to G1. Therefore, it is suggested that there may be a chance to stimulate and enhance the activation of oxytocin receptors on CL following persistent exogenous administration of supraphysiological dosages $\geq 10$ i.u. of oxytocin. Perhaps, it may cause the release of PGF $2 \alpha$ from uterus even at the time of gamma interferon (bTP-1) release during pregnancy in buffalo similar as in ewe (Burgess et al., 1990). Moreover, there may be also synergistic effect of exogenous oxytocin administration on CL lysis (positive feedback loop of PGF $2 \alpha$ and luteal OT) which triggers autocrine or paracrine release of endogenous oxytocin release resulting into more oxytocin receptors activation which indirectly stimulates PGF $2 \alpha$ release from endometrium (Flint et al., 1990; Balaguer, 1999) consequently demises of CL. This leads to ultimately falling in $\mathrm{P} 4$ concentration as reported in numerous studies in cattle (Armstrong and Hansel, 1959; Harms and Malven, 1969; Milvae and Hansel, 1980 and Tan et al., 1982) and in another study in goats (Cooke and Knifton, 1981). However, these results are dissimilar to the findings of many researchers in cattle (Lafrance and Goff, 1985; Gilbert et al., 1989 and Kubo et al., 2018) and in ewes (Flint and Sheldrick, 1985) where they indicated that no change in PGF2M, hence, CL life span increased and no decline found in progesterone concentration subsequently continuous infusion of oxytocin during estrous cycle and early pregnancy.

In present study, it was seen that there was nonsignificant $(\mathrm{P}>0.05)$ embryonic and fetal losses among the treatments. However, there was increase trend towards considerable embryonic as well as fetal losses in oxytocin treated groups as compared to control group. These results are partially similar with earlier studies conducted in dairy buffaloes (Ahmad et al., 2000; Mustafa et al., 2008) and cows (Lemaster et al., 1999; Ahmad et al., 2000; Yildiz and Erisir, 2006; Mustafa et al., 2008). This decrease in embryonic and fetal losses might be suggested due to activation of luteal oxytocinendometrial PGF2 $\alpha$ feedback loop by triggering the release of uterine PGF2 $\alpha$. As a result, it causes the regression of $\mathrm{CL}$ following exogenous oxytocin administration (Lemaster et al., 1999).

In the existing study, $\mathrm{P} 4$ concentration on days; 30 and 45 of post AI was insignificant $(\mathrm{P}>0.05)$ among all treatment groups (G1, G2 and G3) but was 
significantly different $(\mathrm{P} \leq 0.05)$ between oxytocin injected groups (G2 and G3) and control group (G1) on day 60 of post AI. These results of $\mathrm{P} 4$ at days; 30 and 45 in oxytocin treated groups are partially in agreement with the study done in Heifers (Lafrance and Goff, 1985) which unveiled that no significant effect on PGF2 $\alpha$ after oxytocin infusion, hence no change exhibited in P4 concentration in pregnant heifer between days 17-19 but at the same time P4 decreased in cyclic heifers following oxytocin injection (Lafrance and Goff, 1989). This deviation in the results from the other studies may be due to differences in dosages, time duration, breed, specie and environmental differences. Furthermore, these (P4) results after day 45 post $\mathrm{AI}$ are also in line with other studies which revealed that $\mathrm{P} 4$ concentration decreased in successive oxytocin injections in pregnant cows (Donaldson et al., 1970; Milave and Hansel, 1980; Fuchs et al., 1996; Lemaster et al., 1999; Yildiz and Erisir, 2006) and also in ewes (Wathes et al., 1991) where CL development prevented and low pregnancy rate achieved after oxytocin injection. Similarly, Tan et al., (1982) also reported inhibition of progesterone secretion from bovine pregnancy $\mathrm{CL}$ when cultured in vitro with exogenous oxytocin but contrary to the studies conducted by some researchers in non-pregnant cattle (Gilbert et al., 1989) where P4 concentration remained unchanged following oxytocin infusion. This is the first study to be reported in buffaloes. Furthermore, it is suggested to investigate the exogenous oxytocin interaction, GnRH and gonadotropins at pituitary and ovarian level in pregnant animals. Mechanism of action and their pathway information provides strong basis to rule out the reasons behind lower pregnancy rate and higher EFL losses in long term oxytocin administered pregnant animals. Secondly monitoring of myometrial activity and blood flow through Colour Doppler ultrasonography also provides additional information regarding reproductive failure in serviced buffaloes following prolong exogenous oxytocin administration. Moreover, estradiol monitoring also provides useful information regarding oxytocin influence on pregnancy failure in long term administered pregnant lactating buffaloes. In addition, long term exogenous oxytocin administered may be studied to investigate pregnancy failure rate in heifers along with evaluation of oxytocin receptors in pregnant animals in future studies.

Conclusion: It may be concluded that long term OT injections of both low and high doses cause significant losses in terms of increase AI services per conception and decrease pregnancy rate with higher embryonic and fetal losses in Nili-Ravi buffaloes

Acknowledgements: Authors acknowledge the kind support of Vice Chancellor (University of Veterinary and Animal Sciences Lahore, Pakistan), Secretary (Livestock and Dairy Development Department, Punjab, Pakistan),
Higher Education Commission HEC (Pakistan), Dr. Mujahid Senior Scientist NIAB, Faisalabad, Dr. Muhammad Wasim, Dr. Ahmad Zia, Dr. Burhan, Dr. Binyameen, Dr. Sundas and Farm staff (BRI) for their assistance to complete this study.

Funding information: This study was funded by Higher Education Commission HEC of Pakistan under Pin No. 213-52903-2AV2-181.

Conflict of interest: Authors have no conflict of interest with any other.

\section{REFERENCES}

Ahmad, K.M., N. Ahmad, and M.K. Mansoor (2000). Abuses of oxytocin in cows and buffaloes. Pakistan Vet. J. 20(3): 161-162.

Ahmad, I., and M. Aleem (2006). Exogenous administration of oxytocin and its residual effects. Pakistan Vet. J. 26(2): 99-100.

Ali, A. (2015). Seasonal variations of the ovarian activity and pregnancy rate in the Egyptian buffalo cows (Bubalus bubalis). Trop. Anim. Health. Prod. 47(5): 815-818.

Armstrong, D.T., and W. Hansel (1959). Alteration of the bovine estrous cycle with oxytocin. J. Dairy Sci. 42(3): 533-542.

Balaguer, S. (1999). Early pregnancy responsiveness to an oxytocin challenge. J. Undergrad. Res. Uni. Schol. Prog. Uni. Florida.

Barrett, A.J., R.D. Murray, R.M. Christley, H. Dobson, and R.F. Smith (2009). Effects of the administration of oxytocin or carbetocin to dairy cows at parturition on their subsequent fertility. Vet. Rec. 165(21): 623-626.

Burgess, K.M., M.M. Ralph, G. Jenkin, and G.D. Thorburn (1990). Effect of oxytocin and estradiol on uterine prostaglandin release in nonpregnant and early pregnant ewes. Biol. Reprod. 42(5-6): 822-833.

Campanile, G., G. Neglia, B. Gasparrini, G. Galiero, A. Prandi, R. Di-Palo, M.J.D. Occhio, and L. Zicarelli (2005). Embryonic mortality in buffaloes synchronized and mated by AI during the seasonal decline in reproductive function. Theriogenology. 63(8): 2334-40.

Campanile, G., and G. Neglia (2007). Embryonic mortality in buffalo cows. Ital. J. Anim. Sci. 6(2): 119-129.

Campanile, G., G. Neglia, and M.J.D. Occhio (2016). Embryonic and fetal mortality in river buffalo (Bubalus bubalis). Theriogenology. 86: $207-$ 213.

Cooke, R.G., and A. Knifton (1981). Oxytocin-induced oestrus in the goat. Theriogenology. 16(1): 95 97. 
Dash, S., A.K. Chakravarty, A. Singh, A. Upadhyay, M. Singh, and S. Yousuf (2016). Effect of heat stress on reproductive performances of dairy cattle and buffaloes: A review. Vet. World. 9(3): 235-244.

Donaldson, L.E., J.M. Bassett, and G.D. Thorburn (1970). Peripheral plasma progesterone concentration of cows during puberty, oestrous cycles, pregnancy and lactation, and the effects of under-nutrition or exogenous oxytocin on progesterone concentration. J. Endocrinol. 48(4): 599-614.

Duncan, D.B. (1955). Multiple Range and Multiple F Tests. Biometrics. 11(1): 1-42.

Flint, A.P.F., E.L. Sheldrick, T.J. McCann, and D.S.C. Jones (1990). Luteal oxytocin: characteristics and control of synchronous episodes of oxytocin and PGF $2 \alpha$ secretion at luteolysis in ruminants. Domest. Anim. Endocrinol. 7(2):111-124.

Flint, A.P.F., and E.L. Sheldrick (1985). Continuous infusion of oxytocin prevents induction of uterine oxytocin receptor and blocks luteal regression in cyclic ewes. J. Reprod. Fertil. 75(2): 623-631.

Forar, A.L., J.M. Gay, D.D., Hancock, and C.C. Gay (1996). Fetal loss frequency in ten Holstein dairy herds. Theriogenology. 45(8): 1505-1513.

Fricke, P.M. (2002). Scanning the future-ultrasonography as a reproductive management tool for dairy cattle. J. Dairy Sci. 85(8): 1918-1926.

Fuchs, A.R., M.K. Rollyson, M. Meyer, M.J. Fields, J.M. Minix, and R.D. Randel (1996). Oxytocin induces prostaglandin $\mathrm{F} 2 \alpha$ release in pregnant cows: influence of gestational age and oxytocin receptor concentrations. Biol. Reprod. 54(3): 647-653.

Gilbert, C.L., G.E. Lamming, T.J. Parkinson, A.P.F. Flint, and D.C. Wathes (1989). Oxytocin infusion from day 10 after oestrus extends the luteal phase in non-pregnant cattle. J. Reprod. Fertil. 86(1): 203-210.

Gümen, A., A. Keskin, G.Yilmazbas-Mecitoglu, E. Karakaya, S. Cevik, and F. Balci (2011). Effects of GnRH, PGF $2 \alpha$ and oxytocin treatments on conception rate at the time of artificial insemination in lactating dairy cows. Czech. J. Anim. Sci. 58(6): 279-283.

Hansen, P.J. (2014). Early embryonic loss due to heat stress. In John Wiley \& Sons $\left(1^{\text {st }} \mathrm{Ed}\right)$, Bovine Reproduction. Inc; Ames Iowa (USA). 580-588 pp.

Harms, P.G., and P.V. Malven (1969). Modification of bovine luteal function by exogenous oxytocin and progesterone. J. Anim. Sci. 29(1): 25-29.

Heppelmann, M., J. Volland, C. Pfarrer, M. Kietzmann, W. Bäumer, S. Merbach, H.A. Schoon, O.
Wellnitz, M. Schmicke, M. Hoedemaker, and H. Bollwein (2018). Effects of oxytocin and PGF2 $\alpha$ on uterine contractility in cows with and without metritis - an in-vitro study. Anim Reprod Sci. 188 (1) : 144-154.

Iqbal, Z., Z.U. Rahman, F. Muhammad, T. Khaliq, H. Anwar, M.M. Awais, and S. Sadaf (2013). Oxytocin induced oxidative stress in lactating Bubalis bubalis (Nili-Ravi). BMC. Vet. Res. 9(1): 169.

Iqbal, Z., Z.U. Rahman, F. Muhammad, M. Akhtar, M.M. Awais, T. Khaliq, A. Nasir, M. Nadeem, K. Khan, H.M. Arshad, and M.A. Basit (2015). Effect of oxytocin on serum biochemistry, liver enzymes, and metabolic hormones in lactating Nili-Ravi buffaloes. Trop. Anim. Health. Prod. 47(1): 21-27.

Khan, M.S., N. Ahmad, and M.A. Khan (2007). Genetic resources and diversity in dairy buffaloes of Pakistan. Pakistan Vet. J. 27(4): 201-207.

Kubo, T., K. Iga, N. Fukuju, K. Kizaki, T. Osawa,Y. Izaike, and T. Takahashi (2018). Different prostaglandin F2 $\alpha$ secretion in response to oxytocin injection between pregnant and non-pregnant cows: effect of the day of oxytocin challenge test for determining the difference. Anim. Sci. J. 89(2): 332-339.

Lafrance, M., and A.K. Goff (1985). Effect of pregnancy on oxytocin-induced release of prostaglandin F2 $\alpha$ in heifers. Biol. Reprod. 33(5): 1113-1119.

Lafrance, M., A.K. Goff, P. Guay, and D. Harvey (1989). Failure to maintain luteal function: a possible cause of early embryonic loss in a cow. Can. J. Vet. Res. 53(3): 279-284.

Lemaster, J.W., R.C. Seals, F.M. Hopkins, and F.N. Schrick (1999). Effects of administration of oxytocin on embryonic survival in progestogen supplemented cattle. Prostaglandins Other Lipid Mediat. 57(4): 259-268.

Lobago, F. (2007). Reproductive and Lactation Performance of dairy cattle in the Oromia Central Highlands of Ethiopia with special emphasis on the pregnancy period. PhD thesis (published). Division of Reproduction, Department of Clinical Sciences, Faculty of Veterinary Medicine and Animal Science, Swedish University of Agricultural Sciences Uppsala. ISBN: 978-91-85913-20-6,1652-6880, 121.

Mahto, D., B. Singh, A. Adil, and R.K. Verma (2008). Effect of Oxytocin and Cofecu on post insemination conception rate in repeat breeder cattle on subsequent time interval. Vet. World. 1(9): 268-269.

Milvae, R.A., and W. Hansel (1980). Concurrent uterine venous and ovarian arterial prostaglandin $\mathrm{F}$ 
concentrations in heifers treated with oxytocin. J. Reprod. Fertil. 60(1): 7-15.

Mustafa, M.Y., K. Saleem, R. Munir, and T.M. Butt (2008). Effect of oxytocin on the productive and reproductive performance of buffalo and cattle in Sheikhupura-Pakistan (A field study). Livest. Res. Rural Dev. (LRRD). 20(12): 193. http://www.lrrd.org/lrrd20/12/must20193.htm.

Qayyum, A., U. Arshad, M.R. Yousuf, and N. Ahmad (2018). Effect of breeding method and season on pregnancy rate and embryonic and fetal losses in lactating Nili-Ravi buffaloes. Trop. Anim. Health Product. 50(3): 555-560.

Qureshi, M.S., and N. Ahmad (2008). Interaction of calf suckling, use of oxytocin and milk yield with reproductive performance of dairy buffaloes. Anim. Reprod. Sci. 106(3-4): 380-392.

Rigby, S., J. Hill, C. Miller, J. Thompson, D. Varner, and T. Blanchard (1999). Administration of oxytocin immediately after insemination does not improve pregnancy rates in mares bred by fertile or subfertile stallions. Theriogenology. 51(6): 1143-1150.

Rossi, F., F. Righi, S. Romanelli, and A. Quarantelli (2008). Reproductive efficiency of dairy cows under negative energy balance conditions. Ann. Fac. Med. Vet. Univ. Parma. 28 (1): 173-180.

Russo, M., D. Vecchio, G. Neglia, C. Pacelli, A. Prandi, B. Gasparrini, L. Zicarelli, M.J.D. Occhio, and G. Campanile (2010). Corpus luteum function and pregnancy outcome in buffaloes during the transition period from breeding to non-breeding season. Reprod. Dom. Anim. 45 (6): 988-91.

Shahid, R., Z.I. Qureshi, and L.A. Lodhi (2016). Effect of recombinant bovine somatotropin (rbST) and oxytocin on health biomarkers, reproductive performance and milk composition of Nili-Ravi buffaloes (Bubalus bubalis) during spring and summer seasons. Pakistan J. Agric. Sci. 53 (4): 985-990.

Singh, B., F. Saravia, R. Bage, and H. RodríguezMartínez (2005). Pregnancy rates in repeatbreeder heifers following multiple artificial inseminations during spontaneous oestrus. Acta Vet. Scand. 46(1): 1-12.

Tan, G.J.S., R. Tweedale, and J.S.G. Biggs (1982). Effects of oxytocin on the bovine corpus luteum of early pregnancy. J. Reprod. Fertil. 66(1): 7578.

Usmani, R.H., N. Ahmad, P. Shafiq, and M.A. Mirza (2001). Effect of subclinical uterine infection on cervical and uterine involution, estrous activity and fertility in postpartum buffaloes. Theriogenology. 55 (2): 563-571.

Vecchio, D., R. Di-Palo, L. Zicarelli, C. Grassi, A. Cammarano, M.J.D Occhio, and G. Campanile (2007). Embryonic mortality in buffalo naturally mated. Ital. J. Anim. Sci. 6(2): 677-679.

Warriach, H.M., D.M. McGill, R.D. Bush, and P.C. Wynn (2012). Production and reproduction performance of Nili-Ravi buffaloes under field conditions of Pakistan. J. Anim. Plant Sci. 22(3): 121-124.

Wathes, D.C., V.J. Ayad, C.L. Gilbert, S.A. McGoff, and C.M. Wathes (1991). "Influence of oxytocin infusion during oestrus and the early luteal phase on progesterone secretion and the establishment of pregnancy in ewes. J. Reprod. Fertil. 92 (2): 383-391.

Yildiz, A., and Z. Erisir (2006). Effects of exogenous oxytocin on embryonic survival in cows. Acta. Vet. Brno. 75(1): 73-78. 